\title{
Pulmonary circulation of the llama at high and low altitudes
}

\author{
P HARRIS, D HEATH, P SMITH, DR WILliAMS, A RAMIREZ, H KRÜGER, \\ DM JONES
}

From the Cardiothoracic Institute, University of London; Department of Pathology, University of Liverpool; Instituto Veterinario de Investigaciones Tropicales y de Altura, University of San Marcos, Lima, Peru; Department of Pathology, Cayetano Heredia Medical School, Lima, Peru; Department of Veterinary Science, Institute of Zoology, Zoological Society of London

ABSTRACT We have studied the pulmonary circulation of three closely related animals, the llama, alpaca, and guanaco. The mean pulmonary arterial pressure of 12 llamas and one alpaca indigenous to high altitude in the Andes was found to be slightly but significantly higher than that of three llamas and three guanacos born and bred at low altitude in England. On the other hand, the medial thickness of the muscular pulmonary arteries and the relative weights of the two ventricles were the same in three llamas and one alpaca at high altitude as they were in one llama and two guanacos at low altitude. It is concluded that the pulmonary vasoconstrictive response to hypoxia, while present, is greatly reduced in this species and it is suggested that this may have taken place by evolutionary adaptation.

Man and cattle develop pulmonary hypertension when living at high altitude. ${ }^{1-3}$ Confirmatory evidence of the raised pulmonary arterial pressure has come from the demonstration of an increased thickness of the media of the muscular pulmonary arteries and muscularisation of the terminal portions of the pulmonary arterial tree, ${ }^{4-6}$ and from an increase in the weight of the right ventricle relative to the left. ${ }^{7} 8$

There is anatomical evidence that at least two species may be the exception to this rule: the mountain viscacha (Lagidium peruanum) ${ }^{8}$ and the llama (Lama glama). ${ }^{4}$ In these previous studies we observed that in the llama native to high altitude there was no right ventricular hypertrophy and the walls of the pulmonary trunk and small pulmonary arteries were thin.

Banchero and his colleagues ${ }^{10}$ produced evidence in opposition to these observations. They found that the mean pulmonary arterial pressure of three young llamas, born and bred at a low altitude of $260 \mathrm{~m}$ rose from an average of $14 \mathrm{~mm} \mathrm{Hg}$ to $23 \mathrm{~mm} \mathrm{Hg}$ after 10 weeks' residence at an altitude of $3420 \mathrm{~m}$. The breathing of hypoxic gas mixtures caused an increase in the pulmonary arterial pressure, and the breathing of pure oxygen at high altitude lowered

Address for reprint requests: Professor Peter Harris, Cardiothoracic Institute, University of London, 2 Beaumont Street, London W1N 2DX. the pulmonary arterial pressure. One of the animals died and was found to have a pulmonary thromboembolus. Microscopy of the lung of this animal showed some arterioles with distinct muscular walls and some thick-walled pulmonary arteries.

In view of this discrepancy, we decided to take the opportunity provided by an expedition to the Peruvian Andes to make measurements of the pulmonary arterial pressure in llamas in their native high altitude habitat and to examine their pulmonary arteries. We have compared these measurements with similar ones made on animals born in England at approximately sea level.

\section{Methods}

\section{HAEMODYNAMICS}

Measurements of the pulmonary arterial pressure were carried out on 12 llamas (Lama glama) and one alpaca (Lama pacos) at La Raya, Peru, at an altitude of $4200 \mathrm{~m}$. The animals were part of a domestic herd indigenous to high altitude in the research station of the Instituto Veterinario de Investigaciones Tropicales y de Altura. All animals were male. Their ages ranged from 6 months to 3 years and are given in table 1.

Fine polyethylene tubing (PE 60) filled with heparinised saline was introduced into the external jugular vein and floated readily into the pulmonary 
Table 1 Right heart pressures in the llama, guanaco, and alpaca

\begin{tabular}{|c|c|c|c|c|c|c|}
\hline & \multicolumn{6}{|c|}{ Pressures-systolic/diastolic (mean) $\mathrm{mm} \mathrm{Hg}$} \\
\hline & Animal & Age (years) & Pulmonary artery & Right ventricle & Right atrium & $\begin{array}{l}\text { Heart rate } \\
(\mathrm{mm})\end{array}$ \\
\hline $\begin{array}{r}\text { Mean high altitude } \\
S D \pm\end{array}$ & 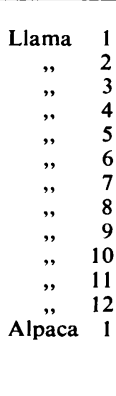 & $\begin{array}{l}3 \\
3 \\
3 \\
3 \\
3 \\
2 \\
1.5 \\
1.5 \\
0.5 \\
0.5 \\
0.5 \\
0.5 \\
2.5\end{array}$ & $\begin{array}{l}16 / 9(12) \\
23 / 9(14) \\
24 / 14(18) \\
15 / 8(12) \\
24 / 5(13) \\
19 / 13(15) \\
21 / 11(15) \\
20 / 9(13) \\
20 / 8(14) \\
19 / 10(14) \\
14 / 4(8) \\
23 / 12(17) \\
18 / 10(13) \\
20 / 9(14) \\
3 \cdot 3 / 2 \cdot 8(2 \cdot 5)\end{array}$ & $\begin{array}{l}\overline{26 /-2} \\
22 /-1 \\
16 / 1 \\
27 /-2 \\
17 / 5 \\
27 / 3 \\
21 / 0 \\
22 /-2 \\
21 / 2 \\
18 /-1 \\
28 / 1 \\
20 / 0 \\
22 / 0 \\
4 \cdot 1 / 2 \cdot 1\end{array}$ & $\begin{array}{l}- \\
(-5) \\
(0) \\
(0) \\
(-7) \\
(4) \\
(-2) \\
(-1) \\
(-4) \\
(0) \\
(-2) \\
(-1) \\
(-1) \\
(-2) \\
2 \cdot 8\end{array}$ & $\begin{array}{l}45 \\
48 \\
57 \\
55 \\
54 \\
59 \\
64 \\
71 \\
79 \\
71 \\
60 \\
94 \\
63 \\
63 \\
13 \cdot 2\end{array}$ \\
\hline Mean sea level & $\begin{array}{cr}\text { Llama } & 13 \\
, " & 14 \\
\text {, } & 15 \\
\text { Guanaco } 1 \\
, " & 2 \\
, " & 3\end{array}$ & $\begin{array}{l}10 \\
3 \cdot 5 \\
2 \cdot 5 \\
0 \cdot 8 \\
1 \cdot 5 \\
1 \cdot 0\end{array}$ & $\begin{array}{l}19 / 11(14) \\
12 / 5(9) \\
5 / 0(3) \\
14 / 7(11) \\
16 / 9(12) \\
13 / 3(8) \\
13 / 6(10) \\
4 \cdot 7 / 4 \cdot 0(3 \cdot 8)\end{array}$ & $\begin{array}{l}22 / 8 \\
12 / 2 \\
7 /-7 \\
19 / 1 \\
16 / 1 \\
13 /-10 \\
15 /-1 \\
5 \cdot 3 / 6 \cdot 6\end{array}$ & $\begin{array}{l}(6) \\
(-2) \\
(-8) \\
-(-1) \\
(-9) \\
(-3) \\
6 \cdot 1\end{array}$ & $\begin{array}{l}48 \\
29 \\
42 \\
65 \\
64 \\
57 \\
51 \\
14 \cdot 0\end{array}$ \\
\hline
\end{tabular}

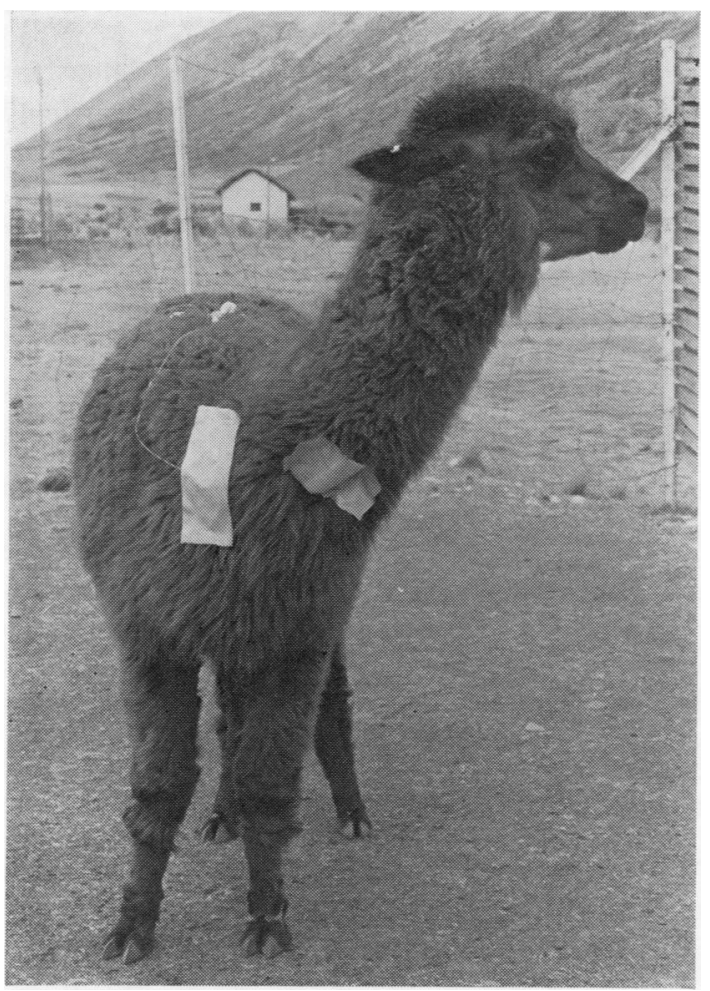

Fig 1 Llama running free in the corral at La Raya. The PE60 tubing can be seen running from the neck to the back of the animal where the infusion pump is located. artery. Pressure was measured by a Statham P23 De transducer linked to a battery-operated amplifier and direct-writing recorder. No general anaesthetic was necessary. When the wave-form indicated that the tip of the catheter was in the pulmonary artery the catheter was removed from the transducer and attached to a battery-driven miniature infusion pump filled with heparinised saline. The miniature pump was then attached to the back of the animal with adhesive strapping and the animal allowed to graze freely within a paddock (fig 1).

After one hour the pressure transducer was again attached and measurements of the pulmonary arterial pressure made. Withdrawal of the catheter confirmed its anatomical position by showing successive right ventricular and right atrial wave forms. Zero pressure was referred to a level half way between the dorsal and ventral surfaces of the thorax at its maximal diameter.

Similar measurements of the pulmonary arterial pressure were carried out in the veterinary department of the Zoological Society of London. Three llamas (Lama glama) and three guanacos (Lama guanicoe) were studied. One was female (llama 13); the rest were male. Their ages ranged from 9 months to 10 years and are given in table 1 . The technique of catheterisation was the same, but all except one of this group of animals received a sedative dose of xylazine before introduction of the catheter. As in the high altitude group, a period of one hour was allowed to elapse between the introduction of the catheter and the recording of pressures which were 
made with the animals standing.

\section{EXAMINATION OF HEART AND LUNGS}

This was carried out on two llamas (4 and 10) and the alpaca in La Raya and on two guanacos (2 and 3) and one llama (14) in London.

The lungs were distended with $10 \%$ formol saline until the pleural surfaces were smooth. When the lungs were fixed, blocks were resected from lung dorsal and ventral to the zero reference point and from the apices and bases. Paraffin sections, $5 \mu \mathrm{m}$ thick, were cut and stained with haematoxylin and eosin, and by the Miller method to demonstrate elastic tissue with a Van Gieson counterstain to demonstrate muscle and collagen. A histological investigation of the various classes of pulmonary blood vessel was carried out. A quantitative study of the medial thickness of the "muscular pulmonary arteries" was made. Measurements were made of the diameter and average thickness of the media of arteries up to $300 \mu \mathrm{m}$ in diameter. Only vessels that were virtually circular in transverse diameter were measured; this method of selection decreased the number of arteries included in each study but avoided error in the measurement of the vessel diameter. The diameter was taken as the mean of two measurements, at right-angles to each other, of the distance between diametrically opposite points on the external elastic lamina. The medial thickness was estimated as the mean of four measurements taken at points approximately equally spaced around the vessel wall. From these data the thickness of the media was expressed as a percentage of the external diameter.

The heart was dissected free of fat. The individual cardiac chambers were then separated and weighed according to the method of Fulton and his associates. ${ }^{11}$

Circumferential rings of pulmonary trunk and aorta were resected $1 \mathrm{~cm}$ distal to the respective valves. The tissue was embedded, and paraffin sections $5 \mu \mathrm{m}$ in thickness were stained by the Miller method for elastic tissue to delineate the media. Ten measurements of the medial thickness of both arteries were made and a mean medial thickness was then calculated for both.

\section{Results}

Llamas, alpacas, and guanacos are so closely related that, to the untrained eye, they are difficult to distinguish. We have, therefore, considered them together.

HAEMODYNAMICS

The measurements of pressure in the pulmonary artery, right ventricle and right atrium are given in table 1 . The average pressures in the pulmonary artery of the high altitude animals were $20 \mathrm{~mm} \mathrm{Hg}$ systolic, $9 \mathrm{~mm} \mathrm{Hg}$ diastolic, and $14 \mathrm{~mm} \mathrm{Hg}$ mean. For the low altitude animals, the average pressures in the pulmonary artery were $13 \mathrm{~mm} \mathrm{Hg}$ systolic, $6 \mathrm{~mm} \mathrm{Hg}$ diastolic, and $10 \mathrm{~mm} \mathrm{Hg}$ mean. The difference in average value for the mean pressure between the two groups of animals had a probability value of $<0.05$ by the $t$ test.

The heart rate tended to be higher at high altitude, especially in the younger animals, but the difference between the two groups was not statistically significant. One of the London animals (llama 13) had a sinus bradycardia of 29 beats $/ \mathrm{min}$. However, its pulmonary arterial pressure was no different from the other members of its group and it has, therefore, been included.

\section{VENTRICULAR WEIGHTS}

The details are given in table 2. Because of the differences in ages there was a wide variation in the size of the hearts. The ratio between the weight of the left ventricle plus septum and the weight of the free wall of the right ventricle, however, remained uninfluenced by age. The average value for this ratio was 2.9 in the high altitude animals and 3.3 in the low altitude animals. The difference was not statistically significant.

\section{MEDIAL THICKNESS OF PULMONARY TRUNK} AND AORTA

The details are given in table 2 . These measurements were also influenced by age. The ratio of the thickness of the media of the pulmonary trunk to that of the aorta was not related to age. The mean value of this ratio was 0.62 in the high altitude animals and 0.57 in the low altitude animals. The difference was not statistically significant.

\section{HISTOLOGY OF THE PULMONARY TRUNK}

In the outer media and extending into the adventitia were thick bands and nodules of smooth muscle. The media also contained much elastic tissue. In the outer half of the media the elastic fibrils were thick, long and wavy, and appeared to be connected by much thinner fibrils. Between the elastic fibrils were bands of smooth muscle arranged circumferentially in the main and progressing in size to the muscular nodules at the junction of media and adventitia described above. In the inner half of the media smooth muscle was less prominent, although individual fibres were seen. Collagen was more in evidence here. In this inner part of the wall of the pulmonary trunk the elastic fibrils were arranged both circumferentially and longitudinally, and as a 
Table 2 Ventricular weights of animals studied

\begin{tabular}{|c|c|c|c|c|c|c|}
\hline & \multicolumn{3}{|c|}{ High altitude animals } & \multicolumn{3}{|c|}{ Low altitude animals } \\
\hline & Llama 4 & Llama 10 & Alpaca I & Guanaco 2 & Guanaco 3 & Llama 14 \\
\hline Age (years) & $2 \cdot 7$ & 0.5 & $2 \cdot 6$ & 1.5 & $1 \cdot 0$ & $3 \cdot 5$ \\
\hline $\begin{array}{l}\text { Ventricles } \\
\text { Weight of right (RV) g } \\
\text { Weight of left }+ \text { septum (LV) g } \\
\text { LV/RV ratio }\end{array}$ & $\begin{array}{l}106 \\
278 \\
2 \cdot 6\end{array}$ & $\begin{array}{l}47 \\
140 \\
3 \cdot 0\end{array}$ & $\begin{array}{c}50 \\
154 \\
3 \cdot 1\end{array}$ & $\begin{array}{c}79 \\
248 \\
3 \cdot 1\end{array}$ & $\begin{array}{l}62 \\
188 \\
3 \cdot 1\end{array}$ & $\begin{array}{l}112 \\
410 \\
3 \cdot 7\end{array}$ \\
\hline $\begin{array}{l}\text { Great vessels } \\
\text { Aortic medial thickness (A) mm } \\
\text { Pulmonary trunk medial thickness } \\
\text { (PT) mm } \\
\text { PT/A }\end{array}$ & $\begin{array}{l}3 \cdot 29 \\
2 \cdot 36\end{array}$ & $\begin{array}{l}2 \cdot 18 \\
1 \cdot 30\end{array}$ & $\begin{array}{l}2.82 \\
1.56\end{array}$ & $\begin{array}{l}2.91 \\
1.54\end{array}$ & $\begin{array}{l}2.48 \\
1.59\end{array}$ & $\begin{array}{l}4 \cdot 66 \\
2 \cdot 46\end{array}$ \\
\hline $\begin{array}{c}\text { Muscular pulmonary arteries } \\
\text { Number of vessels counted } \\
\text { Medial thickness } \% \\
\text { mean } \\
\text { SD }\end{array}$ & $\begin{array}{l}100 \\
4 \cdot 1 \\
1 \cdot 1\end{array}$ & $\begin{array}{r}100 \\
5 \cdot 8 \\
1 \cdot 7\end{array}$ & $\begin{array}{l}50 \\
4 \cdot 4 \\
1 \cdot 3\end{array}$ & $\begin{array}{l}40 \\
6 \cdot 0 \\
2 \cdot 3\end{array}$ & $\begin{array}{l}40 \\
4 \cdot 2 \\
2 \cdot 0\end{array}$ & $\begin{array}{l}25 \\
4 \cdot 6 \\
1 \cdot 3\end{array}$ \\
\hline $\begin{array}{c}\text { External diameter } \% \\
\text { mean } \\
\text { SD }\end{array}$ & $\begin{array}{r}132 \\
57\end{array}$ & $\begin{array}{l}89 \\
53\end{array}$ & $\begin{array}{r}117 \\
60\end{array}$ & $\begin{array}{r}122 \\
57\end{array}$ & $\begin{array}{r}140 \\
61\end{array}$ & $\begin{array}{r}136 \\
60\end{array}$ \\
\hline
\end{tabular}

result even at low magnification this inner zone could be delineated easily. There was a thick internal elastic lamina and immediately beneath this was a very narrow zone of tightly packed elastic fibrils arranged longitudinally. There was no difference in structure between the pulmonary trunk of high and low altitude llamas and the reason for this is that the pulmonary trunk of the llama is very muscular compared to that of man, even at low altitude.

\section{MUSCULAR PULMONARY ARTERIES}

(figs 2 and 3 )

In both the high and low altitude animals the media was thin-walled and composed of circularlyorientated smooth muscle sandwiched between inner

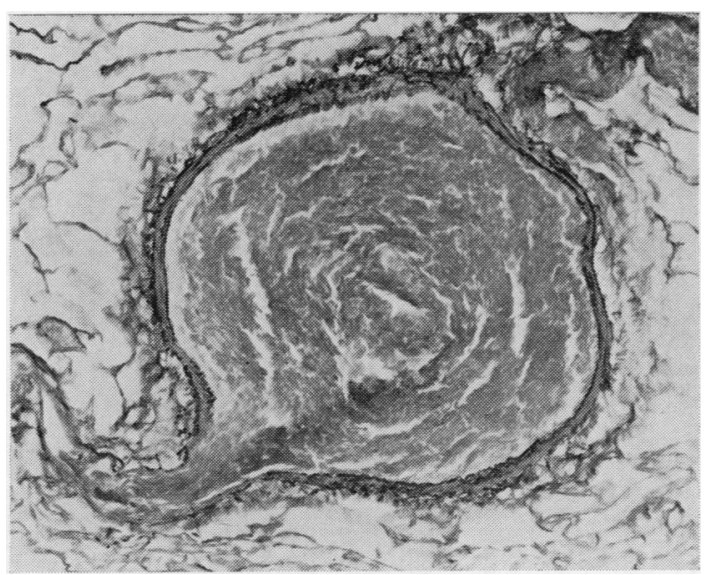

Fig 2 Transverse section of muscular pulmonary artery from llama 4. The media is thin-walled. A pulmonary arteriole originates at the lower left of the vessel. Elastic Van Gieson, original magnification $\times 237$.

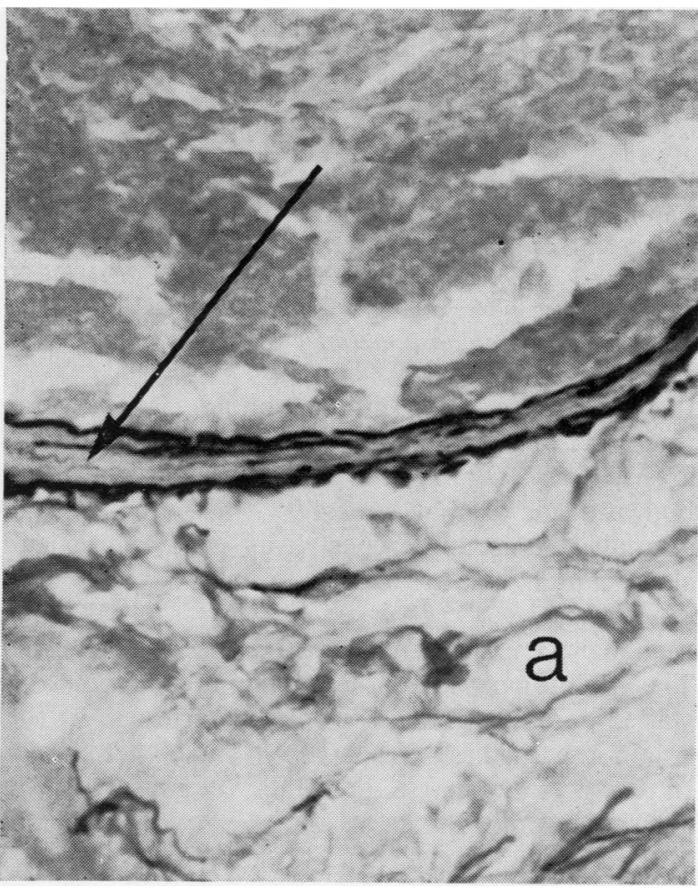

Fig 3 Detail of the media of a muscular pulmonary artery from llama 4. The vessel is thin-walled and its media (arrow) comprises circularly-orientated smooth muscle sandwiched between inner and outer elastic laminae. There is a surrounding adventitia, $a$, of fibrous and elastic tissue. Elastic Van Gieson, original magnification $\times 600$.

and outer elastic laminae. Small wisps of elastic fibril were included in the media between the muscle fibres. There was no intimal proliferation of any type and 


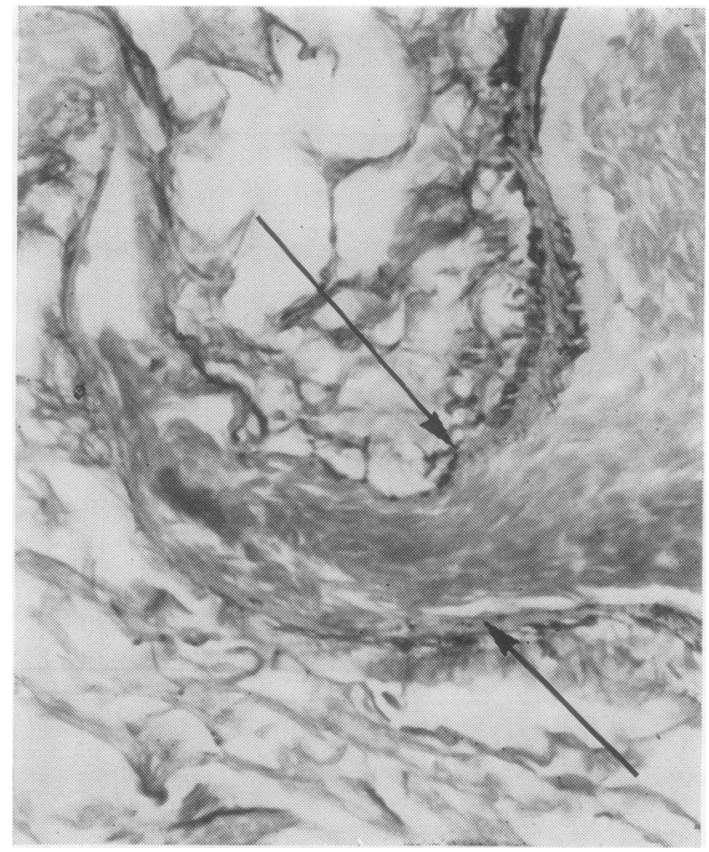

Fig 4 Detail of the origin of the pulmonary arteriole shown in fig 2. The thin media of the parent muscular pulmonary artery peters out at the origin of the pulmonary arteriole (arrows). The wall of the arteriole includes only sparse amounts of smooth muscle.

Elastic Van Gieson, original magnification $\times 600$.

the adventitia was unremarkable. The average thickness of the media of the muscular pulmonary arteris was $4.8 \%$ of the external diameter in the high altitude animals and $4.9 \%$ in the low altitude animals. This difference was not statistically significant.

PULMONARY ARTERIOLES (fig 4)

The pulmonary arterioles originated from thinwalled parent muscular pulmonary arteries. At their origin the media of the parent vessel petered out to leave very sparse amounts of muscle in the arteriolar wall.

\section{Discussion}

Our measurements show that in this group of camelids the pulmonary arterial pressure of those animals native to their normal high altitude habitat is slightly but significantly higher than that of those animals which have been born and bred at low altitude. It seems, therefore, that this species preserves, to a limited extent, the property of hypoxic pulmonary vasoconstriction suggested by the studies in animals taken acutely to high altitude. ${ }^{10}$ The difference between our studies and those of Banchero and his colleagues ${ }^{10}$ lies in the magnitude of the effect.

\section{HAEMODYNAMICS}

The level of pressure in the pulmonary circulation is highly sensitive to the level chosen for zero manometric pressure. Banchero and his associates ${ }^{10}$ chose the shoulder joint as their reference point. In our studies chest radiographs of the llama indicated that the heart occupied the anterior mediastinum (fig 5). In the normal standing position of the animal, the level of the shoulder joint approximated to that of the heart but was substantially below the midheight of the lungs. In order to obtain a figure which was more representative of the pressure in the pulmonary circulation and to allow comparison with man, we, therefore, chose a zero reference level half-way between the dorsal and ventral surfaces of the thorax at its maximal diameter. In a group of 11 llamas we found that this level averaged $8.3 \mathrm{~cm}$ above the level of the shoulder, a distance representing a difference in hydrostatic pressure of approximately $6 \mathrm{~mm} \mathrm{Hg}$.

The average right atrial pressure recorded by Banchero and his group ${ }^{10}$ was $5 \mathrm{~mm} \mathrm{Hg}$ higher than that which our reference level gave, which confirms the difference derived from anatomical measurements. When converted to a mid-thoracic

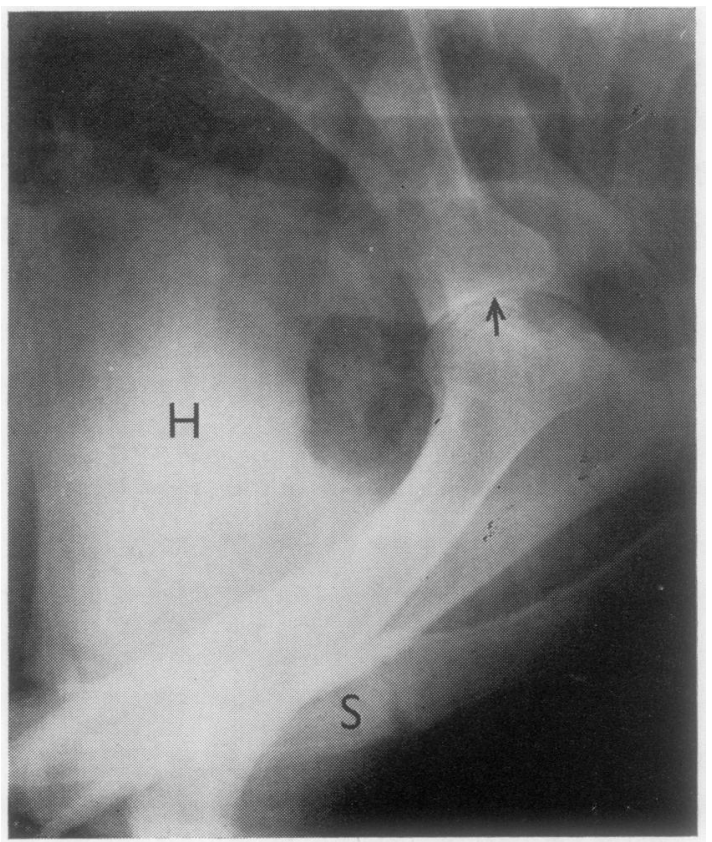

(a) 


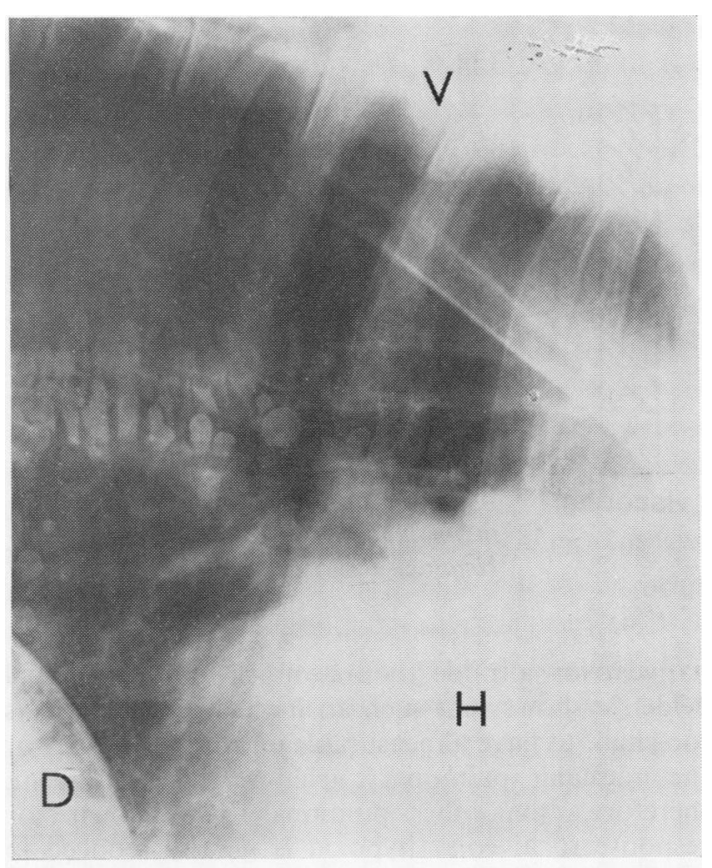

(b)

Fig 5 Lateral radiographs of a llama. (a) The heart $(H)$ lies anteriorly, in contact with the sternum $(S)$. The shoulder joint is indicated by an arrow. (b) The heart $(H)$ lies anteriorly. $V=$ vertebral column, $D=$ diaphragm. Artefactual water marks are present in the lung field. We are indebted to the Nuffield Institute of Comparative Medicine for carrying out these radiographs.

reference level, the average figure for the mean pulmonary arterial pressure found by Banchero et al $^{10}$ in three llamas at low altitude was $8 \mathrm{~mm} \mathrm{Hg}$, which is not substantially different from the figure of $10 \mathrm{~mm} \mathrm{Hg}$ which we observed. Similarly, the average figure for the mean pulmonary arterial pressure found in llamas after they had been transferred to high altitude was $17 \mathrm{~mm} \mathrm{Hg}^{10}$ which is not substantially different from the figure of $14 \mathrm{~mm} \mathrm{Hg}$ which we found in animals indigenous to high altitude. On the other hand, when the pressures measured at low and high altitude are compared, these small differences become magnified, so that the figures of Banchero et al ${ }^{10}$ show a two-fold increase in pressure, while ours show an increase which, while statistically significant, is relatively slight. At the same time the choice of zero reference level influences one's interpretation. Thus, a figure of $17 \mathrm{~mm} \mathrm{Hg}$ for the mean pulmonary arterial pressure does not strike one as abnormally high by comparison with the numbers obtained by standard techniques in man; but, when this is referred to the level of the shoulder, it becomes $23 \mathrm{~mm} \mathrm{Hg}$, which suggests pulmonary hypertension.

\section{WEIGHTS OF VENTRICLES}

The different sizes, shapes, and postures of different animals renders it difficult to arrive at appropriate zero reference levels which will enable comparisons to be made between the pulmonary arterial pressures of different species. For this purpose, therefore, comparative anatomy may be more helpful.

The relative weights of the two cardiac ventricles depends on the relative arterial pressures of the two circulations. At low altitude the ratio of the weight of the left ventricle plus septum to the weight of the free wall of the right ventricle is remarkably constant between 3 and 4 in a variety of species including man. When pulmonary hypertension occurs, the ratio decreases so that the ratio gives an indication whether animals subjected to chronic hypoxia have developed pulmonary hypertension. For instance, we found that subjecting guinea pigs to simulated high altitude at a barometric pressure of $400 \mathrm{~mm} \mathrm{Hg}$ for two weeks decreased the ratio from $3 \cdot 2$ to $2 \cdot 3.12$

In fig 6 we have summarised a number of observations comparing the ventricular ratio in different species indigenous to low and high altitude. The observations on guinea pigs, rabbits, and dogs have been taken from our work books from previous expeditions to the Andes. Those on the llama are from the present study, to which have been added our two previous observations at high altitude ${ }^{9}$ and two observations by Hultgren quoted by Banchero et al. ${ }^{10}$ In guinea pigs, rabbits, and dogs, the ratio is over 3 at low altitude and clearly decreases to less than 3 at high altitude. The ratio in the low altitude llamas is $3 \cdot 3$, which is similar to that of the other three species. However, the ratio falls barely and insignificantly to 3.0 in the high altitude llamas. While, therefore, the haemodynamic measurements show that the pulmonary arterial pressure is slightly but significantly higher in high altitude llamas, this increase is not sufficient to have any substantial effect on the weights of the ventricles, the ratio between which remains similar to that of other species at low altitude. For comparison, fig 6 also shows the ventricular ratio in the mountain viscacha, a species in which there is no histological evidence of pulmonary vasoconstriction. ${ }^{8}$ In this species the average ratio in high altitude animals was $3 \cdot 3$, similar to that found in other species at low altitude.

\section{PULMONARY ARTERIES}

In man the ratio of the medial thickness of the pulmonary trunk to that of the aorta is related to the level of pulmonary arterial pressure. Normally 


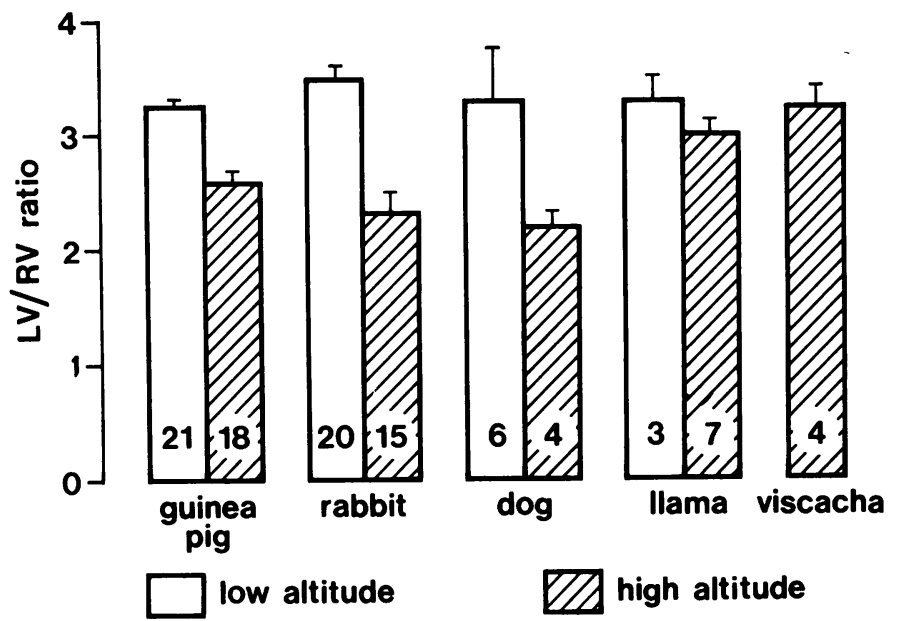

Fig 6 The ratio of the weight of the left ventricle plus septum to the weight of the free wall of the right ventricle in different species at low and high altitude. The numbers of animals together with an indication of the standard error are given with each column. Observations on guinea-pigs, rabbits, and dogs are from our personal records. Those on the llama are from the present study to which have been added two observations at high altitude from Heath et $a^{9}$ and two observations at high altitude from Hultgren, quoted in Banchero et al. ${ }^{10}$ The observations on the mountain viscacha are from Heath et al. ${ }^{8}$

this ratio is in the range of 0.4 to 0.7 but in the presence of significant pulmonary hypertension this ratio exceeds 0.7 and may reach unity. ${ }^{13}$ In the llama both the pulmonary trunk and aorta are very muscular, this almost certainly being a feature of the species. The muscularity is pronounced even in low altitude camelids and we did not detect any increase in the PT/A ratio in the high altitude animals.

Comparison of the structure of the small branches of the pulmonary artery is rendered difficult by the great differences which are found between different species. ${ }^{14}$ Nevertheless, within the same species, residence at high altitude has been shown to give rise to a thickening of the media of these vessels. Abrahams et $a^{15}$ found that the medial thickness increased from $5.2 \%$ to $8.3 \%$ in rats exposed to a simulated altitude of $5500 \mathrm{~m}$ for 33 days. A similar muscularisation of the terminal portions of the pulmonary arterial tree has been noted in several species indigenous to high altitude, including $\operatorname{man}^{5}$ and cattle. ${ }^{6}$

It is clear from table 2 that there was no significant difference between the muscular pulmonary arteries of camelids at high altitude and those at low altitude. The figures correspond with an observation which had been made previously on a llama indigenous to the Peruvian Andes.4 Thus these measurements support those of the weights of the ventricles in failing to demonstrate any substantial effect of pulmonary hypertension in the high altitude animals.

\section{EVOLUTIONARY IMPLICATIONS}

While, therefore, our haemodynamic observations support those of Banchero et al ${ }^{10}$ in showing that the pulmonary arterial pressure is slightly higher in llamas native to high altitude than it is in those native to low altitude, the anatomical and histological evidence shows that such an increase in pressure is too slight to have a measurable effect on the heart or the muscular pulmonary arteries. It would seem, therefore, that the pulmonary vasoconstrictor response to alveolar hypoxia is greatly reduced in the llama.

It is possible that the response has become reduced by natural selection. It seems probable that the evolutionary advantage of the mechanism is to constrict the blood supply to underventilated portions of the lung and thus ensure an equal distribution of ventilation:perfusion ratios and the maintenance of the arterial Po2. The mechanism may well have had its origin early in vertebrate evolution as it has been found to occur in the branchial circulation of fishes. ${ }^{16}$

In a hypoxic environment, such as occurs at high altitude, the homeostatic necessity for an equality of the distribution of the ratio of ventilation to perfusion becomes less important because of the shape of the dissociation curve for haemoglobin. ${ }^{17}$ Thus the advantages of the mechanism for natural selection are minimised. At the same time the disadvantages of global hypoxic pulmonary vasoconstriction became manifest. Pulmonary hypertension increases the after-load on the right ventricle and sudden increases in the pulmonary arterial pressure can give rise to pulmonary oedema which may be fatal.

In this way, hypoxic pulmonary vasoconstriction becomes an incumbrance to survival at high altitude and adaptation by natural selection would be expected to be accompanied by a diminution or elimination of the vasoconstrictor response. It would seem that this is, in fact, what has happened to the llama. 
This work was carried out with the aid of grants from the British Heart Foundation and the Wellcome Trust.

\section{References}

1 Peñaloza D, Sime F, Banchero N, Gamboa R. Pulmonary hypertension in healthy man born and living at high altitudes. Med Thorac 1962;19:449-60.

${ }^{2}$ Heath D, Williams DR. Man at high altitude. Second edition. Edinburgh: Churchill Livingstone, 1981

${ }^{3}$ Hecht HH, Lange RL, Carnes WH, Kuida H, Blake JT. Brisket disease. I. General aspects of pulmonary hypertensive heart disease in cattle. Trans Assoc Am Phys 1959;72:157-72.

4 Heath D, Castillo Y, Arias-Stella J, Harris P. The small pulmonary arteries of the llama and other domestic animals native to high altitudes. Cardiovasc Res 1969; 3:75-8.

${ }^{5}$ Arias-Stella J, Saldaña $M$. The terminal portions of the pulmonary arterial tree in people native to high altitudes. Circulation 1963;28:915-25.

- Alexander AF. The bovine lung: normal vascular histology and vascular lesions in high mountain disease. Med Thorac 1962;19:528-42.

${ }^{7}$ Arias-Stella J, Recavarren S. Right ventricular hypertrophy in native children living at high altitude. Am J Pathol $1962 ; 41: 55-64$.

${ }^{8}$ Heath D, Williams D, Harris $P$, Smith $P$, Krüger $H$, Ramirez A. The pulmonary vasculature of the mountain- viscacha (Lagidium peruanum). J Comp Morphol 1981; in press.

${ }^{9}$ Heath D, Smith P, Williams D, Harris P, Arias-Stella J, $\mathrm{Krüger} \mathrm{H}$. The heart and pulmonary vasculature of the llama (Lama glama). Thorax 1974;29:463-71.

${ }^{10}$ Banchero N, Grover RF, Will JA. High altitude-induced pulmonary arterial hypertension in the llama (Lama glama). Am J Physiol 1971;220:422-7.

1 Fulton RM, Hutchinson EC, Jones AM. Ventricular weight in cardiac hypertrophy. Br Heart $J$ 1952;14: 413-20.

${ }^{12}$ Gloster J, Hasleton PS, Harris P, Heath D. Effects of chronic hypoxia and diet on the weight and lipid content of viscera in the guinea-pig. Environ Physiol Biochem $1974 ; 4: 251-8$.

${ }^{13}$ Heath D, Wood EH, DuShane JW, Edwards JE. The structure of the pulmonary trunk at different ages and in cases of pulmonary hypertension and pulmonary stenosis. J Pathol Bact 1959;77:443-56.

14 Best PV, Heath D. Interpretation of the appearance of the small pulmonary blood vessels in animals. Circulation Res $1961 ; 9: 288-94$.

15 Abraham AS, Kay JM, Cole RB, Pincock AC. Haemodynamic and pathological study of the effects of chronic hypoxia and subsequent recovery on the heart and pulmonary vasculature of the rat. Cardiovasc Res 1971 ; 5:95-102.

16 Satchell GH. Circulation in fishes. London: Cambridge University Press, 1971:93.

${ }^{17}$ Harris P, Heath D. The human pulmonary circulation. Second edition. Edinburgh: Churchill Livingstone, 1977. 